\title{
ESTRATÉGIAS DE ENFRENTAMENTO DO RACISMO NA ESCOLA: UMA REVISÃO INTEGRATIVA
}

\author{
CARVALHO, Daniela Melo da Silva (Brasil, Sergipe, Aracaju) ${ }^{1}$ \\ FRANÇA, Dalila Xavier de (Brasil, Sergipe, Aracaju) ${ }^{1}$ \\ ${ }^{1}$ Universidade Federal de Sergipe \\ ORCID ID: https://orcid.org/0000-0001-7142-778X \\ ORCID ID: https://orcid.org/0000-0002-0431-3034
}

\begin{abstract}
RESUMO
O objetivo deste artigo foi efetuar uma revisão integrativa de literatura sobre as estratégias de enfrentamento do racismo na escola. Foi realizada uma busca nas bases de dados SciELO (Scientific Electronic Library Online), PePSIC (Periódicos Acadêmicos em Psicologia) e Periódicos Capes, utilizando os descritores "racismo", "preconceito racial", "escola", "educação", "combate" e "enfrentamento". O banco final foi constituído por 20 documentos e os temas mais frequentes nos artigos foram: Lei n. 10.639/2003 e formação docente. Foi constatada pouca produção acerca de temas relacionados a questões raciais e educação infantil. Com relação ao enfrentamento, a maioria dos artigos enfatizavam a importância da formação docente e a Lei n. 10.639/2003 como estratégias para o combate do racismo na escola. Foi verificado que os estudos sobre essa temática precisam se expandir, pois as discussões são importantes para aprofundar o tema e o compartilhamento dos recursos utilizados pode contribuir para o enfrentamento do racismo na escola.
\end{abstract}

PALAVRAS-CHAVE

Racismo. Escola. Educação.

\section{STRATEGIES FOR COPING WITH RACISM AT SCHOOL:}

\author{
AN INTEGRATIVE REVIEW
}

\begin{abstract}
The objective of this article was to perform an integrative review of the literature over strategies for coping with racism at school. A search was leaded on SciELO (Scientific Electronic Library Online, PePSIC (Academic Periodicals in Psychology) and Capes Periodicals, using the descriptors "racism", "racial prejudice", "school", "education" and "coping". The final bank was composed by 20 documents and the most frequent themes in the articles were the Law $10.639 / 03$ and teacher training. It was found a low production on themes related to racial issues and early childhood education. In regard to the confrontation, most articles emphasized the importance of teacher training and of the Law $10.639 / 03$ as strategies for coping with racism at school. It was also verified that the studies on this theme need to expand, for the discussions are important to deepen the issue, besides the sharing of resources used can contribute to coping with racism at school.
\end{abstract}

\section{KEYWORDS}

Racism. School. Education. 


\title{
ESTRATEGIAS DE ENFRENTAMIENTO DEL PREJUICIO EN LA ESCUELA: UNA REVISIÓN INTEGRATIVA
}

\begin{abstract}
RESUMEN
El objetivo de este artículo fue efectuar una revisión integrativa de literatura sobre las estrategias de enfrentamiento del racismo en la escuela. Se realizó una búsqueda en las bases de datos SciELO (Scientific Electronic Library Online), PePSIC (Periódicos Académicos en Psicología) y Periódicos Capes, utilizando los descriptores "racismo", "prejuicio racial", "escuela", "educación", "combate" y "enfrentamiento". El banco final fue constituido por 20 documentos y los temas más frecuentes en los artículos fueron: Ley n. 10.639/2003 y formación docente. Se constató poca producción acerca de temas relacionados a cuestiones raciales y educación infantil. Con respecto al enfrentamiento, la mayoría de los artículos enfatizaban la importancia de la formación docente y la Ley n. 10.639/2003 como estrategias para el combate del racismo en la escuela. Se verificó que los estudios sobre esta temática necesitan expandirse, pues las discusiones son importantes para profundizar el tema y compartir los recursos utilizados puede contribuir al enfrentamiento del racismo en la escuela.
\end{abstract}

PALABRAS CLAVE

Racismo. Escuela. Educación.

\section{INTRODUÇÃO}

No Brasil, a exclusão escolar atinge níveis alarmantes. Segundo a Pesquisa Nacional de Amostra por Domicílio (PNAD) (2016), no Brasil, 2.802 .258 crianças e adolescentes de 4 a 17 anos estão fora da escola. Sabe-se também que essa exclusão afeta principalmente crianças provenientes de camadas mais vulneráveis da população, que já são privadas de outros direitos constitucionais. Isso se torna claro ao refinar essa amostra para raça e cor da pele, neste caso $64 \%$ das crianças e adolescentes entre 4 e 17 anos que estão fora da escola são pretas e pardas e 36\% são brancas. Esses dados se tornam ainda mais graves com o aumento da faixa etária e da escolaridade, pois, segundo o Censo Demográfico, somente 4,34\% da população negra entre 15 e 24 anos possuem o ensino superior completo (IBGE, 2010).

As políticas de educação brasileiras ainda têm sido insuficientes para enfrentar as desigualdades raciais que marcam historicamente o acesso, a permanência e a aprendizagem das crianças e adolescentes negros nas escolas brasileiras. Além disso, a trajetória escolar desses alunos, durante esse longo período de escolarização, é 
igualmente preocupante. Esse fato não se refere aos discentes negros que as condições econômicas familiares não Ihes permitem esse acesso ou lhes fazem desistir durante 0 percurso, refere-se aos que continuam lá, nas escolas brasileiras, e que lutam todos os dias para serem iguais e terem as mesmas chances de qualquer outra criança, enfrentando todos os dias o preconceito pichado nas paredes da escola ou escondido entre seus muros.

Preconceito consiste em uma atitude hostil que pode ser direcionada a um grupo como um todo ou a uma pessoa em função da sua pertença a um grupo social (ALLPORT, 1971). Fica claro, a partir dessa definição, que o preconceito está ligado a grupos sociais, mais ainda aos grupos socialmente desvalorizados. No caso do racismo, um indivíduo e/ou toda uma categoria social são definidos como diferentes, por isso são discriminados ou excluídos com base em alguma marca física externa, a qual é ressignificada em termos de uma marca cultural interna (LIMA; VALA, 2004).

A manifestação discriminatória dentro do processo educativo tem gerado uma série de agressões físicas e simbólicas que acarreta sofrimento no cotidiano dos alunos, principalmente dos negros. A escola, que é um dos lugares fundamentais para a construção da identidade do indivíduo, acaba funcionando como mais um lugar onde o preconceito e a discriminação são desenvolvidos e alimentados (FERREIRA; CAMARGO, 2011).

Muitos pesquisadores têm se preocupado com as relações existentes no dia a dia escolar e suas consequências para os envolvidos. Cavalleiro (1998), em sua pesquisa sobre racismo e preconceito na educação infantil, traz dados sobre aspectos recorrentes que acontecem no ambiente escolar, como a não existência de cartazes nos espaços de convivência da escola que possam expressar a diversidade das crianças brasileiras no que se refere à cor de pele, ou, por exemplo, o tratamento diferenciado ao expressar afeto por parte dos professores para seus alunos. Esse aspecto também foi evidenciado no relato da professora Lígia na pesquisa de Ferreira e Camargo (2011), que, ao expressar sua experiência escolar como aluna negra, revelou a sensação que ela tinha de que nunca conseguiria aprender e as lembranças de que nunca teve 0 carinho dos professores da educação infantil que as estudantes brancas tinham.

Apesar de conseguirmos observar claramente o racismo presente nos dados das pesquisas citadas, ele ainda é negado no discurso brasileiro, inclusive no discurso 
escolar. Isso fica claro ao analisar os resultados de pesquisa sobre a concepção dos professores a respeito da manifestação do racismo nas escolas em geral e nas escolas onde atuam. É possível perceber que, quando questionados sobre o preconceito racial, os professores negam ou consideram um problema do outro, defendendo que na sua escola não existe racismo (SANTOS, 2014). A negação do racismo tem uma dimensão individual, como também social, pois quem nega a prática racista não se preocupa somente em não parecer racista, mas em defender a imagem de seu endogrupo de que não são racistas (RIEDEMANN; STEFONI, 2015).

O reconhecimento de que o racismo está presente nos discursos e nas práticas escolares é importante para promover uma educação antirracista, e o primeiro passo para que isso aconteça é entender que essas práticas refletem uma ideologia maior, que defende que sujeitos ocupam uma posição de inferioridade em relação a outros (RIEDEMANN; STEFONI, 2015). É preciso acabar com o discurso de que não é da competência da escola discutir questões ligadas à formação humana, incluindo nelas as questões raciais, pelo contrário, o tema precisa estar presente desde a formação de professores. A escola é responsável pelo enfrentamento do preconceito nos seus espaços, e isso só é possível com a adoção de mudanças concretas que possibilitem o surgimento de novos valores e a construção de novas práticas (GOMES, 2005).

A união de estratégias utilizadas pela educação, com estudos e pesquisas da psicologia, proporcionou a testagem de várias intervenções a fim de verificar qual seria a mais efetiva na diminuição do preconceito em crianças. Foram utilizadas quatro abordagens de diminuição do preconceito com 621 crianças de 5 a 11 anos de 22 escolas de Kent, com o objetivo de testar as mudanças referentes às atitudes das crianças para com os deficientes e refugiados. Todas as intervenções utilizaram as quatro abordagens de forma intercalada, sendo elas: a abordagem multicultural, a color-blind, a abordagem de grupos comuns e a educação contra estereótipo, sendo os resultados avaliados e comparados. A abordagem que se mostrou mais efetiva foi a multicultural, a qual chama a atenção para as diferenças entre os grupos sociais, mas apresenta as diferenças como sendo positivas. Dessa forma, essa abordagem acredita que o preconceito será reduzido se as crianças forem ensinadas sobre a diversidade de uma forma positiva. As intervenções realizadas nesta pesquisa citada com as crianças utilizaram as abordagens teóricas através de técnicas de leitura de histórias (RUTLAND; BROWN, 2005).

Educação \& Formação, Fortaleza, v. 4, n. 12, p. 148-168 set./out. 2019

DOI: https://doi.org/10.25053/redufor.v4i12.974

http://seer.uece.br/redufor 
Ainda sobre estratégias que poderiam ser utilizadas para a diminuição do preconceito, uma meta-análise de mais de 500 estudos foi realizada para tentar responder à pergunta de como o contato intergrupal poderia reduzir preconceitos. Foram testados três mediadores mais estudados relacionados ao contato: o conhecimento sobre o grupo externo, a redução da ansiedade pelo contato intergrupal e o aumento da empatia proporcionada pelo contato. Os resultados mostraram que o conhecimento sobre o outro grupo não demonstrou ter efetividade na diminuição do preconceito, ao contrário da redução da ansiedade: por muitas vezes, acompanhar a iniciação da interação entre os grupos permitiu uma redução significativa do preconceito (PETTIGREW; TROPP, 2006).

Qual seria então o papel da escola no combate ao racismo? Que estratégias estão sendo utilizadas para o seu enfrentamento no espaço escolar? A realidade dos dados apresentados neste artigo torna claro que a escola precisa assumir sua função social de combate ao racismo. Dessa forma, surge a necessidade de conhecer os recursos que estão sendo utilizados pela educação e pela escola para o enfrentamento do preconceito e do racismo, de forma a estimular mais publicações na área para que estas possam contribuir com ações efetivas de combate ao racismo na esfera escolar e educacional.

O presente artigo se propõe a efetuar uma revisão integrativa de literatura sobre as estratégias de enfrentamento do racismo na escola. Por ser uma forma de pesquisa que utiliza a literatura como fonte de dados, a revisão integrativa pode facilitar no levantamento dos recursos que estão sendo empregados pela escola para 0 enfrentamento do racismo. Esse tipo de investigação foi escolhido porque busca reunir evidências relacionadas a uma estratégia de intervenção ou mapear conhecimentos sobre um tema, sendo úteis para integrar informações sobre estudos realizados, auxiliando profissionais a se manterem atualizados e facilitando as modificações da prática cotidiana como consequência da pesquisa (ROMAN; FRIEDLANDER, 1998).

Esse tipo de pesquisa se faz necessário pelo fato de que não foram encontradas, nas bases de dados analisadas e em outras buscas, revisões que integrem aspectos de combate ao racismo pela escola ou educação. Embora no Brasil esteja havendo iniciativas interventivas no sentido de enfrentar e combater o racismo na escola, não tem havido uma sistematização desses estudos, de sorte que pouco se sabe sobre 
o que tem sido feito por pesquisadores individuais. Diante disso, este estudo possibilita essa sistematização. Acredita-se que este artigo possa contribuir, ao reunir as principais estratégias encontradas na literatura, com a ampliação do debate acerca da temática racial e sobretudo propiciar que as escolas coloquem em prática o grande desafio de mudar suas práticas pedagógicas para o combate do racismo no ambiente escolar.

\section{MÉTODO}

Este estudo busca realizar uma revisão integrativa da literatura que relacione estratégias de enfrentamento do racismo utilizadas pela escola ou educação. A revisão integrativa é um método que sintetiza resultados de pesquisas sobre um determinado tema ou questão de maneira sistemática e ordenada, objetivando contribuir para 0 conhecimento desse tema (ROMAN; FRIEDLANDER, 1998).

Para atender ao objetivo do estudo, empreendeu-se uma busca nas bases dados: Scientific Eletronic Library Online (SciELO), Periódicos Acadêmicos em Psicologia (PePSIC) e no portal de periódicos da Coordenação de Aperfeiçoamento de Pessoal de Nível Superior (Capes). A consulta foi realizada a partir dos termos de busca com operadores boolianos (racismo $O R$ preconceito racial) $A N D$ (escola $O R$ educação) $A N D$ (combate $O R$ enfrentamento). Como o interesse desta revisão foi conhecer os recursos que estão sendo utilizados para o enfrentamento do racismo na escola, optou-se por não delimitar na busca o período de publicação. Assim, para não haver o risco de excluir estudos importantes em virtude apenas da data de sua divulgação, foram incluídos todos os trabalhos publicados até setembro de 2018, quando a busca foi realizada.

O levantamento das publicações com os termos boolianos gerou um total de 331 documentos (SciELO: 12, PePSIC: 0 e periódicos da Capes: 319). Na primeira triagem, a qual tinha por objetivo excluir os trabalhos duplicados entre as bases, foram excluídos sete trabalhos, restando um total de 324 documentos. Em seguida, foi feita uma seleção a partir do título da publicação e dos seus respectivos resumos, na busca de estudos que se enquadrassem nos critérios de inclusão estabelecidos, que foram: (1) ter como tema principal o racismo ou o preconceito racial e (2) estar relacionado à área da educação ou ter relação com a escola. Dos 324 documentos restantes, 290 não atenderam aos critérios de inclusão, restando nessa etapa 34 documentos. 
Os textos completos das 34 publicações selecionados foram recuperados e submetidos a uma nova seleção, a partir de critérios de exclusão, sendo eles: (1) não trazer uma proposta de combate ou enfrentamento ao preconceito e (2) não ter o texto completo disponível na internet. Nessa seleção, 14 atenderam aos critérios de exclusão, dos quais dois não tinham o texto completo disponível na internet e 12 não traziam uma proposta de combate ou enfrentamento ao preconceito. Restaram, portanto, 20 publicações, que compuseram o banco final de análise deste estudo; seus principais dados estão resumidos no Quadro 1, adiante. É importante frisar que todas as publicações encontradas a partir das estratégias metodológicas foram artigos científicos; as teses e dissertações não atenderam aos critérios de inclusão, não fazendo parte, pois, do corpus final deste estudo.

Os resultados seguintes serão apresentados, no primeiro momento, de forma descritiva, tendo como base a análise de elementos relativos ao ano de publicação dos trabalhos, aos periódicos responsáveis pelas publicações, à natureza dos estudos e ao público-alvo. No segundo momento, serão analisados os dados dos conteúdos dos artigos científicos, através das temáticas e estratégias de enfrentamento apresentadas.

\section{RESULTADOS}

\subsection{ANÁLISE DESCRITIVA DO CORPUS INVESTIGADO}

A publicação de trabalhos que relacionam a temática do racismo e escola, por via de estratégias de enfrentamento, teve início em 2003, dentro dos critérios especificados neste estudo. Apesar de terem sido encontrados artigos sobre a temática publicados em anos anteriores, eles não traziam uma proposta de enfrentamento ao problema do racismo na escola, os quais, portanto, não foram incluídos na revisão. A partir dessa data, o número de publicações não seguiu um padrão linear ao longo dos anos. Em 2008, a área atingiu o número máximo de trabalhos sobre o tema publicados em um único ano (quatro) e somente em 2017 chegou-se novamente a esse número de artigos com essa temática publicados em um ano. A lista do ano de publicação dos artigos bem como seus temas e objetivos também podem ser observados no Quadro 1.

Educação \& Formação, Fortaleza, v. 4, n. 12, p. 148-168 set./out. 2019 
Os 20 trabalhos encontrados neste estudo foram publicados em 19 revistas diferentes, sendo que apenas duas são editadas no exterior. Com relação ao idioma, o artigo de Arocha et al. (2007) foi publicado em espanhol, o de São Paulo (2010) em inglês e os outros 18 em português. A maioria das revistas (18) publicou apenas um artigo sobre o tema, somente uma, a Revista de Estudos Feministas, publicou dois artigos do presente corpus analisado. Apesar de a grande maioria dos trabalhos ter sido publicada em periódicos diferentes, 12 deles foram em periódicos relacionados à educação, tendo em comum a preocupação em incentivar a pesquisa acadêmica, ampliar o debate educacional e socializar o conhecimento produzido na área de educação. Com relação à natureza dos estudos, pôde-se observar que, dos artigos submetidos à análise, 12 deles são teóricos, seis são empíricos e dois trazem uma proposta de intervenção.

Sobre os participantes dos estudos em questão, é preciso ressaltar que os artigos foram selecionados tendo como pré-requisito trazer uma proposta de combate ou enfrentamento às questões étnico-raciais ligadas à escola, dessa forma muitos deles são teóricos e não apresentam participantes. Foi utilizado nessa análise o termo "foco da ação", ou seja, a que ou a quem se destinam as estratégias sugeridas pelos estudos (ver Quadro 1). Os alunos foram o foco de apenas quatro pesquisas: uma delas se referia a alunos da educação infantil, uma a alunos do ensino fundamental e duas a alunos do ensino médio. O maior número de pesquisas (sete) tinha suas estratégias de combate ao preconceito destinadas aos professores. Outras tinham como foco de ação os livros didáticos (três), o ensino superior (três) e o público em geral (três).

No que diz respeito aos objetivos dos 20 estudos analisados, os artigos apresentaram proximidade no tocante a seus objetivos gerais e a seus temas principais. Os temas "o currículo e o ensino no combate ao racismo" e "a formação de professor e relações raciais" apareceram nos objetivos de um número maior de artigos, com um número de cinco artigos em cada tema. A efetivação da Lei n. 10.639/2003 apareceu nos objetivos de quatro artigos do corpus analisado. E os temas que trouxeram as contribuições das políticas afirmativas no combate ao preconceito e às expressões do preconceito nos livros didáticos contemplaram os objetivos de seis estudos, sendo três em cada temática. 
Quadro 1 - Dados do corpus extraído dos artigos científicos publicados nas bases de dados pesquisadas sobre racismo e escola

\begin{tabular}{|c|c|c|c|c|}
\hline Autores & Objetivos & Natureza & Foco da ação & $\begin{array}{l}\text { Estratégia de } \\
\text { enfrentamento }\end{array}$ \\
\hline Valente, 2005 & $\begin{array}{l}\text { Ação afirmativa, } \\
\text { relações raciais e } \\
\text { educação básica }\end{array}$ & Teórico & $\begin{array}{c}\text { Alunos da } \\
\text { educação infantil } \\
\text { e professores }\end{array}$ & $\begin{array}{l}\text { Palestras sob a forma de } \\
\text { diálogo participativo e } \\
\text { formação de professores }\end{array}$ \\
\hline $\begin{array}{l}\text { Carvalho e } \\
\text { Castro, } 2017\end{array}$ & $\begin{array}{l}\text { Currículo, racismo e o } \\
\text { ensino de Língua } \\
\text { Portuguesa }\end{array}$ & Teórico & $\begin{array}{l}\text { Alunos do ensino } \\
\text { médio }\end{array}$ & $\begin{array}{c}\text { Por meio do currículo, } \\
\text { adotar práticas discursivas } \\
\text { que permitam a } \\
\text { fragilização das estruturas } \\
\text { rígidas e tradicionais }\end{array}$ \\
\hline $\begin{array}{l}\text { Francisco Júnior, } \\
2008\end{array}$ & $\begin{array}{l}\text { Educação antirracista } \\
\text { e contribuições do } \\
\text { ensino de Ciências }\end{array}$ & Teórico & $\begin{array}{l}\text { Professores de } \\
\text { Ciências e } \\
\text { alunos }\end{array}$ & $\begin{array}{c}\text { Fazer uma releitura dessa } \\
\text { ciência e utilizar o discurso } \\
\text { do professor para sublinhar } \\
\text { os conhecimentos dos } \\
\text { povos africanos }\end{array}$ \\
\hline $\begin{array}{l}\text { Abreu e Mattos, } \\
2008\end{array}$ & $\begin{array}{c}\text { Diretrizes Curriculares, } \\
\text { Relações Étnico- } \\
\text { Raciais e Ensino de } \\
\text { História }\end{array}$ & Teórico & $\begin{array}{l}\text { Professores de } \\
\text { História }\end{array}$ & $\begin{array}{c}\text { Mudanças práticas no } \\
\text { ensino de História através } \\
\text { das aulas dos professores } \\
\text { e projetos }\end{array}$ \\
\hline Rohden, 2009 & $\begin{array}{l}\text { Formação do } \\
\text { professor e combate } \\
\text { às discriminações }\end{array}$ & Empírico & $\begin{array}{l}\text { Professores do } \\
\text { ensino } \\
\text { fundamental } \\
\end{array}$ & $\begin{array}{l}\text { Curso de formação a } \\
\text { distância de professores do } \\
\text { ensino fundamental }\end{array}$ \\
\hline Santana, 2016 & $\begin{array}{c}\text { Preconceito, } \\
\text { discriminação e os } \\
\text { livros didáticos de } \\
\text { História }\end{array}$ & Teórico & Livros didáticos & $\begin{array}{c}\text { A inserção de debates } \\
\text { acadêmicos nos livros } \\
\text { didáticos, incluindo eventos } \\
\text { de relevante transformação } \\
\text { na História do Brasil }\end{array}$ \\
\hline $\begin{array}{l}\text { Aguiar, Piotto e } \\
\text { Correa, } 2015\end{array}$ & $\begin{array}{l}\text { Relações étnico- } \\
\text {-raciais e formação } \\
\text { docente }\end{array}$ & Teórico & $\begin{array}{l}\text { Professores e } \\
\text { alunos da } \\
\text { educação infantil }\end{array}$ & Formação docente \\
\hline $\begin{array}{c}\text { Rosemberg, } \\
\text { Basilli e Silva, } \\
2003\end{array}$ & $\begin{array}{l}\text { Racismo e livros } \\
\text { didáticos }\end{array}$ & Teórico & Livros didáticos & $\begin{array}{l}\text { Parâmetros Curriculares } \\
\text { Nacionais e o PNLD }\end{array}$ \\
\hline $\begin{array}{l}\text { Silva e Dias, } \\
\quad 2013\end{array}$ & $\begin{array}{c}\text { O racismo e as } \\
\text { contribuições da } \\
\text { pedagogia institucional }\end{array}$ & Teórico & Geral & $\begin{array}{c}\text { A utilização dos princípios } \\
\text { da pedagogia institucional } \\
\text { para o enfrentamento do } \\
\text { racismo na escola }\end{array}$ \\
\hline $\begin{array}{l}\text { Trevisan e } \\
\text { Dalsin, } 2014\end{array}$ & $\begin{array}{l}\text { Livros didáticos de } \\
\text { Matemática e } \\
\text { Multiculturalismo }\end{array}$ & Empírico & Livro didático & $\begin{array}{l}\text { A utilização de imagens } \\
\text { nos livros didáticos de } \\
\text { Matemática que favoreçam } \\
\text { práticas sociais mais } \\
\text { tolerantes }\end{array}$ \\
\hline Cunha, 2015 & $\begin{array}{l}\text { Disciplina de História e } \\
\text { implementação da Lei } \\
\text { n. 10.639/2003 }\end{array}$ & Teórico & $\begin{array}{l}\text { Professores de } \\
\text { História }\end{array}$ & $\begin{array}{l}\text { Utilização de um fato } \\
\text { histórico para a } \\
\text { implementação da Lei } \\
\text { n. } 10.639 / 2003\end{array}$ \\
\hline $\begin{array}{l}\text { Gomes, Boeing e } \\
\text { Alexandre, } 2012\end{array}$ & $\begin{array}{c}\text { Tecnologia da } \\
\text { informação e exclusão }\end{array}$ & Teórico & Geral & $\begin{array}{c}\text { Contribuição das Tls para } \\
\text { o combate da } \\
\text { discriminação }\end{array}$ \\
\hline $\begin{array}{l}\text { Matos, Bispo e } \\
\text { Lima, } 2017\end{array}$ & $\begin{array}{l}\text { Educação antirracista } \\
\text { e a Lei n. 10.639/2003 }\end{array}$ & Empírico & $\begin{array}{l}\text { Estudantes do } \\
\text { ensino médio e } \\
\text { técnico }\end{array}$ & $\begin{array}{c}\text { Evento anual com } \\
\text { produções culturais e } \\
\text { apresentações de } \\
\text { trabalhos desenvolvidos } \\
\text { em sala de aula }\end{array}$ \\
\hline
\end{tabular}

Educação \& Formação, Fortaleza, v. 4, n. 12, p. 148-168 set./out. 2019

DOI: https://doi.org/10.25053/redufor.v4i12.974

http://seer.uece.br/redufor 
Quadro 1 - Dados do corpus extraído dos artigos científicos publicados nas bases de dados pesquisadas sobre racismo e escola

\begin{tabular}{|c|c|c|c|c|}
\hline Autores & Objetivos & Natureza & Foco da ação & $\begin{array}{c}\text { Estratégia de } \\
\text { enfrentamento }\end{array}$ \\
\hline Pinto, 2017 & $\begin{array}{l}\text { Lei n. 10.639/2003 e } \\
\text { manifestações } \\
\text { artísticas e culturais }\end{array}$ & Empírico & $\begin{array}{l}\text { Participantes do } \\
\text { projeto de } \\
\text { extensão, alunos } \\
\text { e docentes } \\
\end{array}$ & $\begin{array}{l}\text { Produção de materiais } \\
\text { bibliográficos, cartilhas, } \\
\text { vídeos, um blog e um } \\
\text { curso de extensão }\end{array}$ \\
\hline $\begin{array}{c}\text { Santos, } \\
\text { Cavalleiro, } \\
\text { Barbosa e } \\
\text { Ribeiro, } 2008 \\
\end{array}$ & $\begin{array}{c}\text { Ações afirmativas e } \\
\text { cotas }\end{array}$ & Teórico & Ensino superior & $\begin{array}{l}\text { Implementação de políticas } \\
\text { públicas de ações } \\
\text { afirmativas pelo Estado }\end{array}$ \\
\hline $\begin{array}{l}\text { Weller e Silveira, } \\
2008\end{array}$ & $\begin{array}{c}\text { Ações afirmativas e } \\
\text { cotas }\end{array}$ & Teórico & Ensino superior & $\begin{array}{c}\text { Ações afirmativas e cotas } \\
\text { para a entrada no ensino } \\
\text { superior por cotas }\end{array}$ \\
\hline $\begin{array}{c}\text { Orlando e } \\
\text { Ferreira, } 2014\end{array}$ & $\begin{array}{l}\text { Diversidade étnico- } \\
\text {-racial e formação de } \\
\text { professores }\end{array}$ & Empírico & $\begin{array}{l}\text { Professores de } \\
\text { línguas do } \\
\text { ensino } \\
\text { fundamental e } \\
\text { médio }\end{array}$ & $\begin{array}{c}\text { Formação continuada a } \\
\text { respeito dessa temática } \\
\text { para os professores }\end{array}$ \\
\hline $\begin{array}{l}\text { Moura e Autiello, } \\
2017\end{array}$ & $\begin{array}{c}\text { Jornal negro na escola } \\
\text { e a Lei n. } 10639 / 2003\end{array}$ & $\begin{array}{l}\text { Proposta de } \\
\text { intervenção }\end{array}$ & $\begin{array}{l}\text { Alunos do ensino } \\
\text { fundamental }\end{array}$ & $\begin{array}{l}\text { Utilização do jornal como } \\
\text { atividade permanente para } \\
\text { a educação das } \\
\text { diversidades étnico-raciais }\end{array}$ \\
\hline $\begin{array}{l}\text { Arocha, Guevara, } \\
\text { Londoño, Moreno } \\
\text { e Rincón, } 2007 \\
\end{array}$ & $\begin{array}{l}\text { Racismo e formação } \\
\text { docente }\end{array}$ & $\begin{array}{l}\text { Proposta de } \\
\text { intervenção }\end{array}$ & $\begin{array}{c}\text { Professores da } \\
\text { educação básica } \\
\text { e média } \\
\end{array}$ & $\begin{array}{l}\text { Programa de formação } \\
\text { permanente de docentes }\end{array}$ \\
\hline São Paulo, 2010 & $\begin{array}{l}\text { Ações afirmativas, } \\
\text { política de cotas }\end{array}$ & Empírico & Ensino superior & $\begin{array}{l}\text { Ações afirmativas e cotas } \\
\text { para a entrada no ensino } \\
\text { superior }\end{array}$ \\
\hline
\end{tabular}

Fonte: Elaboração própria (2019).

\subsection{ANÁLISE DE CONTEÚDO DO CORPUS INVESTIGADO}

Partindo do objetivo do presente trabalho em se realizar uma revisão integrativa de literatura sobre as estratégias de enfrentamento do racismo na escola, foi realizada uma categorização fundamentada pela análise de conteúdo (BARDIN, 2011), que possibilitou a construção de categorias a partir do agrupamento das estratégias de enfrentamento obtidas nos artigos selecionados.

Para uma melhor exposição dos resultados encontrados, o conteúdo das estratégias de combate que apareceram nos artigos que compuseram esta revisão foi classificado em cinco categorias: contribuições do currículo e do ensino no combate ao preconceito; expressão do preconceito nos livros didáticos e estratégias de combate nesse contexto; estratégias de combate embasadas na formação docente; estratégias de 
combate embasadas nas políticas afirmativas e no sistema de cotas; e implementação da Lei n. 10.639/2003 como estratégia de combate.

\subsubsection{Contribuições do currículo e do ensino no combate ao preconceito}

As possíveis contribuições das diretrizes curriculares e do ensino para o enfrentamento do racismo na escola apareceram em cinco artigos do corpus analisado. Em dois deles - Abreu e Mattos (2008) e Carvalho e Castro (2017) -, enfatiza-se a importância das diretrizes curriculares para a valorização da cultura africana e principalmente para o respeito à história de resistência do povo africano. Outro ponto comum nos resultados dos dois trabalhos é o reconhecimento da existência nas diretrizes curriculares de muitas orientações sobre as questões étnico-raciais, mas aparece também a crítica de que, para as propostas serem efetivadas na prática, ainda é preciso um longo caminho, pois os autores consideram que somente as diretrizes não são suficientes para erradicar preconceitos.

Os outros três trabalhos também discutem esses aspectos, são eles: Cunha (2015), Francisco Júnior (2008) e Silva e Dias (2013). Eles estão mais voltados para o combate ao preconceito através do ensino em sala de aula. Nos resultados de Francisco Júnior (2008) aparecem sugestões para as aulas de Ciências, a exemplo de conhecimentos do povo africano importantes para a Ciência, mas não reconhecidos como advindos da África. Exemplos importantes da Biologia, como cuidados com higiene, doenças infecciosas e anestesia, e exemplos da Química e Física aparecem no trabalho. No trabalho de Cunha (2015), há sugestões para a disciplina de História, suscitando a relevância em se debater a história da Insurreição de Queimados, importante na resistência contra a escravidão no Brasil, a qual está fora dos debates das escolas públicas. Já o trabalho de Silva e Dias (2013) traz contribuições da Pedagogia Institucional na mediação das questões na sala de aula, principalmente nas questões étnico-raciais.

Os artigos que compõem essa categoria discutem a importância de se efetivarem as diretrizes curriculares, bem como trazem aspectos práticos de como combater o preconceito e o racismo através do ensino de várias disciplinas em sala de

Educação \& Formação, Fortaleza, v. 4, n. 12, p. 148-168 set./out. 2019 
aula, aprimorando e ampliando os currículos escolares com conhecimentos que fortalecem os aspectos étnicos e culturais.

\subsubsection{Expressão do preconceito nos livros didáticos e estratégias de combate nesse contexto}

Uma parte dos trabalhos revisados, três artigos, faz referência à expressão do racismo e do preconceito nos livros didáticos. Os resultados de dois artigos - Santana (2016) e Trevisan e Dalsin (2015) - trazem críticas pertinentes ao racismo que aparece nos livros didáticos e enfatizam que é preciso ter cuidado com a forma generalizada que os temas aparecem nos livros. Sobre os livros de Matemática, Trevisan e Dalsin (2015) criticam as imagens que deixam transparecer um discurso de igualdade e tolerância que não condiz com a realidade da sociedade.

Essa temática também aparece no trabalho de Rosemberg, Basilli e Silva (2003), que apresentam resultados extraídos de uma revisão de literatura sobre preconceito nos livros didáticos. Os dados retratam que o foco dos estudos sobre os livros didáticos é voltado para o ensino fundamental, sendo rara a análise de livros da educação infantil. As disciplinas mais privilegiadas nas análises são História e Língua Portuguesa e o foco das análises está voltado para o texto e as ilustrações, faltando estudos sobre a recepção dos livros por parte dos alunos.

Os três estudos analisados fazem alusão à expressão do preconceito manifestado através dos livros didáticos e enfatizam a importância de se estar atento à construção dos livros e materiais pedagógicos, visto que são importantes fontes de conhecimento e informação para o desenvolvimento infantil e também um importante aliado no combate ao preconceito.

\subsubsection{Estratégias de combate embasadas na formação docente}

A importância da formação docente para o enfrentamento do racismo no espaço escolar aparece como temática em cinco artigos dos 20 analisados neste estudo. $O$ trabalho de Orlando e Ferreira (2014) traz em seus resultados as dificuldades enfrentadas pelos professores ao lidarem com a temática étnico-racial. O despreparo, a 
tomada de decisões equivocadas e o argumento de que não tem formação para lidar com esses aspectos na prática são os resultados encontrados no estudo desses autores.

Outros dois artigos - Arocha et al. (2007) e Rohden (2009) - têm em comum a preocupação com a formação docente, acreditando ser uma importante aliada no combate ao racismo na escola. Os artigos trazem duas propostas de enfrentamento: um programa de formação continuada de professores e um curso de formação a distância para professores. Os dados dos resultados versam sobre a melhoria da visibilidade da África depois da execução do programa, vontade de realizar mudanças na própria escola e atenção redobrada à manifestação do preconceito na escola depois do curso realizado.

Os últimos dois artigos que compõem esta categoria trazem narrativas de expressões do preconceito no cotidiano da educação infantil envolvendo questões étnico-raciais. Um deles foi o estudo de Aguiar, Piotto e Correa (2015), que apresentam dados sobre a observação de estagiários de Pedagogia sobre situações de preconceito e discriminação por parte de professores da educação infantil. Comentários sobre as características físicas dos alunos negros, valorização e comparação das qualidades dos discentes negros e brancos e diferença entre os afetos dispensados aos alunos pela sua cor fizeram parte dos dados coletados pelos estagiários. Apesar disso, os estagiários relataram apresentar dificuldades em reconhecer situações de preconceito e discriminação. O outro artigo, de Valente (2005), apresenta dados semelhantes sobre a manifestação de preconceito no contexto da educação infantil. Esse estudo traz uma proposta de intervenção com os estudantes da educação infantil para trabalhar o reconhecimento da diferença e inverter o processo que tende a associar tal reconhecimento aos estereótipos negativos.

Todas as pesquisas elencadas neste tópico retratam a dificuldade dos professores para lidarem com as situações de preconceito que aparecem na sala de aula, sendo elas da educação infantil ou de outros níveis de ensino, e, por consequência, sugerem que uma importante estratégia para o enfrentamento do racismo e da discriminação na escola é o investimento na formação de professores. 


\subsubsection{Estratégias de combate embasadas nas políticas afirmativas e no sistema de cotas}

Dos artigos analisados neste estudo, três deles - São Paulo (2010), Santos et al. (2008) e Weler e Silveira (2008) - discutem as políticas afirmativas e cotas como uma proposta para o enfrentamento do racismo e das desigualdades sociais. Os resultados apontam a diversidade de opiniões a esse respeito. Os discentes do estudo de São Paulo (2010) demonstram interesse na implantação dos programas de ações afirmativas, mas não existe concordância em relação às razões e se as medidas resolverão 0 problema. Já o estudo de Santos (2008) retrata que alguns cientistas também são contrários às políticas afirmativas, pois fazem previsão sem fundamento histórico e se afastam da produção de conhecimento fundamentada em pesquisa.

\subsubsection{A implementação da Lei $n$. 10.639/2003 como estratégia de combate}

Projetos culturais desenvolvidos na escola são apresentados como estratégias de enfrentamento nos trabalhos de Autiello e Moura (2017), Matos, Bispo e Lima (2017) e Pinto (2017). Autiello e Moura (2017) trouxeram a utilização do jornal em ambiente escolar como atividade permanente para a educação das diversidades étnico-raciais. Matos, Bispo e Lima (2017) propuseram um projeto anual desenvolvido na escola promovendo o diálogo entre estudantes, professores e convidados, para discutir a temática étnico-racial e difundir a educação antirracista. Pinto (2017) elabora um projeto de extensão localizando ações e expressões da cultura afro-brasileira.

Todos os três trabalhos citados fazem referência à utilização dessas ideias como efetivação da Lei n. 10.639/2003, que incluiu a obrigatoriedade do estudo da história e cultura afro-brasileira nas escolas brasileiras. O outro trabalho que completa esta categoria é o de Gomes, Boeing e Alexandre (2012), que indicam, como estratégia de enfrentamento, um conhecimento específico da Tecnologia da Informação (TI), trazendo aspectos relacionados à prevenção e ao combate ao racismo através dos avanços tecnológicos. 


\section{DISCUSSÃO}

Considerando a importância de estudos que relacionam a temática entre racismo e escola e as contribuições sociais que os resultados desses estudos podem gerar, pode-se afirmar que a quantidade de artigos publicados sobre o tema no país ainda é restrita. Dos 324 artigos não duplicados encontrados inicialmente, apenas 34 diziam respeito ao racismo e estavam relacionados à escola ou à educação. Como o objetivo do trabalho foi efetuar uma revisão integrativa de literatura sobre as estratégias de enfrentamento do racismo na escola, ao se refinar a pesquisa para selecionar os artigos que trouxessem uma proposta de combate ao racismo voltado para essa temática, esse número caiu para 20 artigos, número considerado pequeno, tendo em vista que não foi delimitado ano para a busca dos artigos. Isso não significa que não houve avanços no combate ao racismo no ambiente escolar e educacional, significa que muitas práticas com essa finalidade estão sendo realizadas sem a pretensão de divulgação e consequentemente não estão sendo convertidas em artigos científicos, o que dificulta 0 progresso dos estudos científicos pertinentes ao racismo.

No tocante aos participantes dos artigos analisados, chamados neste estudo de público-alvo, percebeu-se que, dos 20 artigos, os alunos foram o foco de apenas quatro pesquisas, dentre as quais apenas uma se referia ao público da educação infantil. No Brasil, há pouca produção acerca de temas vinculados a questões étnico-raciais e educação infantil. O estudo de Cavalleiro (1998), por exemplo, sobre racismo e preconceito na educação infantil, traz dados sobre aspectos recorrentes que acontecem no ambiente escolar para as crianças negras dessa faixa etária. Mas, desde essa data, a autora já discutia o fato da pouca publicação de estudos sobre crianças negras na educação infantil, e isso não mudou muito com o passar do tempo. $\mathrm{Na}$ análise do preconceito nos livros didáticos, também foram encontrados dados parecidos. A revisão sistemática de literatura de Rosemberg, Basilli e Silva (2003), que analisaram a expressão do preconceito em livros didáticos, aponta que o foco das análises para esse tipo de temática são os livros do ensino fundamental, não aparecendo análise em livros da educação infantil. A própria legislação federal (Lei n. 10.639/2003) que alterou as propostas curriculares para o enfrentamento do preconceito e discriminação racial foi

Educação \& Formação, Fortaleza, v. 4, n. 12, p. 148-168 set./out. 2019 
dirigida para o ensino fundamental e médio, negligenciando a educação infantil dessa obrigatoriedade.

Quando o corpus do estudo em questão foi dividido pelas suas temáticas, pôde-se observar que $20 \%$ dos artigos enfatizavam a importância da formação docente como principal estratégia para o enfrentamento do racismo na escola. Gomes (2005) também reforça a importância de as questões raciais serem discutidas dentro da escola e estarem presentes na formação de professores, mas, além disso, a autora enfatiza que essa discussão tem que estar acompanhada da adoção de novas práticas, possibilitando mudança de valores.

Nos resultados apresentados na categoria "formação docente", apareceu o despreparo dos professores para lidarem e identificarem as questões raciais na escola, e as estratégias sugeridas pelos estudos foram um programa de formação continuada e um curso de formação a distância para professores. Esses dados corroboram os de outros estudos que enfatizam a importância do papel dos professores no combate ao racismo e como isso está fortemente vinculado à sua formação como docente. Os cursos destinados à formação de professores estão focados em métodos de conteúdos e estratégias de ensino, reflexos de uma educação acrítica que pode ser observada nas escolas em geral. É preciso que as práticas docentes busquem reconhecer a diversidade e enfatizar as diferenças de forma positiva, como aponta a abordagem multicultural, e que sejam discutidas, ainda na formação docente, intervenções eficazes para a diminuição do preconceito (RUTLAND; BROWN, 2005).

Nos aspectos curriculares e de ensino, enfatizou-se a importância de se cumprir as diretrizes curriculares, e os estudos sugeriram ideias propositivas voltadas a disciplinas específicas de ensino de sala de aula. Essas estratégias demonstram novas práticas pedagógicas, incluindo aspectos raciais nas áreas de Ciências, História, Química e Física. A ampliação das áreas de conhecimento contempladas foi importante, pois a lei que inclui no currículo oficial da rede de ensino a obrigatoriedade da temática "História e Cultura Afro-Brasileira" não define que essa temática está restrita à disciplina de História nem a datas comemorativas. Pelo contrário, os autores sugerem que a questão racial deve passar pela ação docente, gestão escolar, currículo, projeto político e pedagógico da escola e ser refletida em todos os momentos educacionais (GOMES, 2005; MACEDO, 2016).

Educação \& Formação, Fortaleza, v. 4, n. 12, p. 148-168 set./out. 2019 
Outra temática que apareceu em mais $20 \%$ da amostra foi o cumprimento da Lei n. 10.639/2003. As estratégias de enfrentamento que apareceram nos trabalhos analisados foram projetos culturais, projetos de extensão, um projeto de TI e a circulação de um jornal impresso como atividade contínua para a educação das diversidades étnico-raciais, com vistas a adensar as ações de combate ao racismo e à discriminação na escola. Os projetos culturais e de extensão sugeridos coadunam-se com a literatura de combate ao preconceito. Através desses eventos culturais, é possível estreitar o contato entre os diferentes grupos sociais, ampliando o conhecimento a respeito do outro grupo e diminuindo a ansiedade que muitas vezes acompanha a iniciação da interação entre os grupos, como sugerida pelo estudo de Pettigrew e Tropp (2006). O jornal impresso sugerido como estratégia também pode ser um importante veículo de informação sobre os grupos étnicos e sobre a diversidade. Enfatizar a diferença de uma maneira positiva, mediante a veiculação do jornal, pode ser um ótimo instrumento de redução de preconceitos, como verificado no estudo de Rutland e Brown (2005).

É preciso considerar, contudo, que os resultados obtidos por esta revisão indicam que os estudos concernentes à temática que relaciona racismo e educação precisam se expandir em âmbito local e nacional, visto que as informações e discussões são importantes para aprofundar o tema e principalmente divulgar os recursos que estão sendo utilizados para enfrentar o racismo.

\section{CONSIDERAÇÕES FINAIS}

O presente artigo teve como objetivo efetuar uma revisão integrativa de literatura sobre as estratégias de enfrentamento do racismo na escola. Essa análise proporcionou a verificação do que vem sendo publicado sobre a temática do racismo e do preconceito na área da educação e principalmente que recursos estão sendo utilizados para combatê-los. Foi possível constatar que formação docente, projetos culturais e artísticos, mudanças curriculares e no ensino e combate ao preconceito nos livros didáticos foram estratégias que apareceram como sugestões dos estudos analisados.

Esta pesquisa apresenta algumas limitações, como o fato de ter se restringido a apenas três bases de dados, não tendo encontrado resultados com os descritores utilizados em uma delas. É importante enfatizar que não foram encontradas nas bases

Educação \& Formação, Fortaleza, v. 4, n. 12, p. 148-168 set./out. 2019 
de dados pesquisadas revisões de literatura que relacionassem a temática racial e a escola e mais ainda que trouxessem práticas de enfrentamento do preconceito e do racismo nesse ambiente. Estudos futuros poderiam aumentar os resultados encontrados, ampliando a pesquisa para sites de educação e escola ou que tratem de questões raciais, em busca de práticas desenvolvidas por professores que efetivam ações antirracistas, mas que não publicam em revistas científicas.

Espera-se que esta revisão seja uma contribuição para aqueles que se interessam pela temática étnico-racial e se preocupam com o que se tem realizado para combater o racismo e o preconceito nos espaços escolares e em outros espaços sociais, suscitando novas pesquisas e novas estratégias de enfrentamento.

\section{REFERÊNCIAS}

ABREU, M.; MATTOS H. Em torno das "Diretrizes Curriculares Nacionais para a Educação das Relações Étnico-Raciais e para o Ensino de História e Cultura Afro-Brasileira e Africana": uma conversa com historiadores. Estudos Históricos, Rio de Janeiro, v. 21, p. 5-20, 2008.

AGUIAR, M. M.; PIOTTO, D. C.; CORREA, B. C. Relações étnico-raciais e formação docente: situações de discriminação racial na educação infantil. Revista Eletrônica de Educação, São Carlos, v. 9, n. 2, p. 373-388, 2015.

ALLPORT, G. W. La naturaleza del prejuicio. 4. ed. Buenos Aires: Eudeba Universitaria, 1971.

AROCHA, J. et al. Elegguá y respeto por los afrocolombianos: una experiencia con docentes de Bogotá en torno a la Cátedra de Estudios Afrocolombianos. Revista de Estudios Sociales, Bogotá, n. 27, p. 94-105, 2007.

BARDIN, L. Análise de conteúdo. Lisboa: 70, 2011.

BRASIL. Lei n. 10.639, de 9 de janeiro de 2003. Altera a Lei n. 9.394, de 20 de dezembro de 1996, que estabelece as Diretrizes e Bases da Educação Nacional, para incluir no currículo oficial da Rede de Ensino a obrigatoriedade da temática "História e Cultura Afro-Brasileira", e dá outras providências. Diário Oficial [da] República Federativa do Brasil, Poder Executivo, Brasília, DF, 10 jan. 2003.

CARVALHO, I. B.; CASTRO, A. C. Currículo, racismo e o ensino de Língua Portuguesa: as relações étnico-raciais na educação e na sociedade. Educação e Sociedade, Campinas, v. 38, n. 138, p. 133-151, 2017. 
CAVALLEIRO, E. S. Do silêncio do lar ao silêncio escolar: racismo, preconceito e discriminação na educação infantil. 1998. 240 f. Dissertação (Mestrado em Educação) Programa de Pós-Graduação em Educação, Universidade de São Paulo, São Paulo, 1998.

CUNHA, G. O. Memória da Insurreição do Queimado (1845-1850) Serra-ES: a precursora da Lei n. 10.639/2003. Revista Simbiótica, Vitória, v. 2, n. 2, p. 1-14, 2015.

FERREIRA, R. F.; CAMARGO A. C. As relações cotidianas e a construção da identidade negra. Psicologia: Ciência e Profissão, Maranhão, v. 31, n. 2, p. 374-389, 2011.

FRANCISCO JÚNIOR, W. E. Educação anti-racista: reflexões e contribuições possíveis do ensino de Ciências e de alguns pensadores. Ciência \& Educação, Bauru, v. 14, n. 3, p. 397-416, 2008.

GOMES, I. A. N.; BOEING, K. C.; ALEXANDRE, I. J. Exclusão e desigualdade no mundo globalizado. Revista Eventos Pedagógicos, Sinop, v. 3, n. 2, p. 377-385, 2012.

GOMES, N. L. Educação e relações raciais: refletindo sobre algumas estratégias de atuação. In: MUNANGA, K. (Org.). Superando o racismo na escola. 2. ed. Brasília, DF: MEC, 2005. p. 143-154.

IBGE - Instituto Brasileiro de Geografia e Estatística. Censo demográfico de 2010. Rio de Janeiro: IBGE, 2010.

IBGE - Instituto Brasileiro de Geografia e Estatística. Pesquisa Nacional de Amostra por Domicílio: síntese de indicadores. Rio de Janeiro: IBGE, 2016.

LIMA, M. E. O.; VALA, J. As novas formas de expressão do preconceito e do racismo. Estudos de Psicologia, Natal, v. 9, n. 3, p. 401-411, 2004.

MACEDO, A. A gestão escolar democrática e a implementação da educação antirracista na escola. Revista Espaço Acadêmico, Maringá, v. 16, n. 187, p. 106-120, 2016.

MATOS, M. S.; BISPO, A. M. C.; LIMA, E. A. C. Educação antirracista e a Lei 10.639/03: uma proposta de implementação a partir do novembro negro do IFBA. Holos, Natal, v. 2, p. 349-359, 2017.

MOURA, A. L. C.; AUTIELLO, S. L. M. A imprensa negra como possibilidade estratégica de trabalho para a formação leitora no espaço escolar. Entreletras, Araguaína, v. 8, n. 2, p. 282-300, 2017.

ORLANDO, A. F.; FERREIRA, A. J. A sensibilização sobre a diversidade étnico-racial na formação inicial e/ou continuada de professores de línguas. Acta Scientiarum, Maringá, v. 36, n. 2, p. 207-216, 2014. 
PETTIGREW, T. F.; TROPP, L. R. How does intergroup contact reduce prejudice? Metaanalytic tests of three mediatours. Conference of the Society for the Psychological Study of Social Issues held in Long Beach, California, 2006.

PINTO, K. C. G. Baixada afro-brasileira: valorização das manifestações artísticas e culturais. Relacult, Jaguarão, v. 3, p. 109-120, 2017.

RIEDMANN, A.; STEFONI, C. Sobre el racismo, su negación y las consecuencias para una educación anti-racista en la enseñanza secundaria chilena. Polis, Santiago, v. 14, n. 42, p. 191-216, 2015.

ROHDEN, F. Gênero, sexualidade e raça/etnia: desafios transversais na formação do professor. Cadernos de Pesquisa, São Paulo, v. 39, n. 136, p. 157-174, 2009.

ROMAN, A. R.; FRIEDLANDER, M. R. Revisão integrativa de pesquisa aplicada à Enfermagem. Cogitare Enfermagem, Curitiba, v. 3, n. 2, p. 109-112, 1998.

ROSEMBERG, F.; BASILLI, C.; SILVA, P. V. B. Racismo em livros didáticos brasileiros e seu combate: uma revisão da literatura. Educação e Pesquisa, São Paulo, v. 29, n. 1, p. 125-146, 2003.

RUTLAND, A.; BROWN, R. Reducing prejudice in children: extended report. PhD Thesis of Lindsey - University of Kent, 2005.

SANTANA, M. S. Uma polêmica historiográfica e sua permanência espectral na história escolar. Revista Ibero-Americana de Estudos em Educação, Araraquara, v. 11, n. 3, p. 1481-1495, 2016.

SANTOS, C. F. Escola e preconceito: relações raciais na ótica dos professores. 2014. 135 f. Dissertação (Mestrado em Psicologia Social) - Programa de Pós-Graduação em Psicologia Social, Universidade Federal de Sergipe, São Cristóvão, 2014.

SANTOS, S. A. et al. Ações afirmativas: polêmicas e possibilidades sobre igualdade racial e o papel do Estado. Estudos Feministas, Florianópolis, v. 16, n. 3, p. 913-929, 2008.

SÃO PAULO, E. Preliminary studies on affirmative action in a Brazilian university. Revista de Administração Mackenzie, São Paulo, v. 11, n. 3, p. 27-45, 2010.

SILVA, T. R.; DIAS, A. A. O racismo sob a forma de violência silenciosa e as contribuições da Pedagogia Institucional no seu enfrentamento. Revista Reflexão e Ação, Santa Cruz do Sul, v. 21, n. 1, p. 72-92, 2013.

TREVISAN, A. C. R.; DALSIN, A. O que as imagens dos livros didáticos de Matemática nos dizem sobre multiculturalismo? Educação, Matemática, Pesquisa, São Paulo, v. 16, n. 2, p. 459-478, 2014. 
VALENTE, A. L. Ação afirmativa, relações raciais e educação básica. Revista Brasileira de Educação, Rio de Janeiro, n. 28, p. 62-77, 2005.

WELLER, W.; SILVEIRA, M. Ações afirmativas no sistema educacional: trajetórias de jovens negras da universidade de Brasília. Estudos Feministas, Florianópolis, v. 16, n. 3, p. 931-947, 2008.

\section{Daniela Melo da Silva Carvalho (Brasil, Sergipe, Aracaju)}

Universidade Federal de Sergipe (UFS)

Mestranda em Psicologia pela UFS. Psicóloga da UFS. Atua como psicóloga educacional no Colégio de Aplicação (UFS).

Lattes: <http://lattes.cnpq.br/6494341372049479>.

E-mail: <danielamelopsi@hotmail.com>.

\section{Dalila Xavier de França (Brasil, Sergipe, Aracaju)}

Universidade Federal de Sergipe (UFS)

Doutora em Psicologia Social pelo Instituto Superior de Ciências do Trabalho e da Empresa, Portugal.

Professora titular da UFS.

Lattes: <http://lattes.cnpq.br/0621095177117818>.

E-mail: <dalilafranca@gmail.com>.

Recebido em 27 de fevereiro de 2019.

Aceito em 18 de junho de 2019. 